\title{
The future of remote work in Japan: Covid-19's implications for international human resource management
}

\author{
Hitoshi Iwashita
}

\begin{abstract}
A B S T R A C T
Objective: The objective of this article is to elaborate how the form of remote work can be hindered in an institutional cultural context in non-Western countries.

Research Design \& Methods: The article adopts data collection based on public report and news release in reference to the current academic literature of human resource management.

Findings: The article finds that the institutional contexts of non-Western countries, unlike those of Western countries, may hinder or limit remote work because of a poor fit between remote work and human resource management (HRM). The article reveals that the cultural context of non-Western countries, such as Japan, may hinder remote work because of collectivism, high context, high power distance, and high uncertainty avoidance. Implications \& Recommendations: The article implicates a possible diversity of how remote work can be implemented in relation to the institutional and cultural contexts of both Western and non-Western countries, such as Japan.
\end{abstract}

Contribution \& Value Added: The article contributes to future international human resource management by showing that there are some institutional and cultural hindrances to remote work in certain countries. The text contributes to future international business and human resource management by showing that other non-Western countries may have similar problems in terms of the execution of remote work due to contexts that are different institutional and cultural from Western examples.

\begin{tabular}{llll}
\hline $\begin{array}{l}\text { Article type: } \\
\text { Keywords: }\end{array}$ & research article & \\
JEL codes: & Covid-19 pandemic; remote work; Japanese firms; managerial work; HRM practice \\
\hline \multicolumn{1}{c}{ Received: 25 February 2021 } & Revised: 11 May 2021 & Accepted: 2 June 2021 \\
\hline
\end{tabular}

\section{Suggested citation:}

Iwashita, H. (2021). The future of remote work in Japan: Covid-19's implications for international human resource management. Entrepreneurial Business and Economics Review, 9(4), 7-18. https://doi.org/10.15678/EBER.2021.090401

\section{INTRODUCTION}

The Covid-19 pandemic has completely changed the landscape of strategy, organizations, and human resource management. During the pandemic, many people started to work at home instead of commuting to the workplace, bringing all work online by using online interaction tools (e.g. Zoom, Microsoft Meeting, and Google Hangouts). This tendency to adopt remote work may not simply be a temporary solution to the Covid-19 pandemic but may also be a permanent move to allow employees to work full time at home. Current studies tend to assume that remote work is not only inevitable but also triggers a change into a new style of work in the future (Collings et al., 2021). This change makes extensive use of information technologies (IT), such as collaboration software, online meetings, and communication tools. In particular, this change makes sense in North American and European countries, and some service industries suit remote work better than others (e.g. information technology and finance industries). Indeed, an iconic move towards permanent remote work was announced by Google, even following the end of this pandemic. The move to remote work is about to be gradually taken for granted, not only because it protects employees against the Covid-19 pandemic but also 
because it promotes the employees' productivity and motivation, especially those who are eager to keep a healthy balance between work and life, along with a high level of well-being.

This shift towards remote work may not be universally promoted or equally adopted across countries in the same way, simply because of the local institutional and cultural context in which employees work in a given country. In international human resource management (HRM), there are always variations in institutional and cultural practices between home and host countries. Each country has different institutional profiles whose influence includes regulatory and normative forces from institutional actors, such as lobbying, bank, state, education, trade union, and non-profit organizations, along with buyers and suppliers (Scott, 2008). These institutional actors are assumed to enable and constrain certain HRM practices. They also affect the national economy based on either liberal market economies (LMEs), which are based on competition, or coordinated market economies (CMEs), which are based on collaboration across institutional actors. Moreover, cultural contexts can also affect the implementations of certain HRM, especially because of power distance, collectivism, and individualism, but also high- and low-context communication (Hall, 1973; Hofstede, 2001; Hofstede, Hofstede, \& Minkov, 2010). The high-performance work system was formulated in the US culture - based on high individualism and low power distance - may not always be accepted in Asian countries, such as Japan, due to the local low individualism and high-power distance (Abo, 2015).

This article considers how the form of remote work can be hindered in the institutional cultural context of non-Western countries. Consequently, it reviews desktop search news and public reports of remote work in Japan from 2020 to 2021 in reference to theoretical constructs of institutional and cultural theories. The article analyses the implementation of remote work and generates implications for HRM practices.

The rest of the article is divided into five sections. The first section reviews the existing literature with a focus on relevant institutional and cultural theories. The next section briefly explains the research method, including data collection and analysis. The third section describes findings and discusses how both institutional and cultural constraints enable the implementation of remote work. The final section concludes by outlining the limitations observed in this study and by recommending avenues for future research.

\section{MATERIALS AND METHODS}

The article examines the possibility that the institutional and cultural contexts of Japan may hinder the implementation of remote work during the Covid-19 pandemic and later. The study stems from institutional and cultural theories (Scott, 2008; Hofstede, 2001; Hofstede, Hofstede, \& Minkov, 2010), which strongly implicate how differently remote work can be implemented in the context of Japan. Using current literature regarding news and reports of remote work before and during the Covid-19 pandemic, mainly in Western countries, this study elaborates why remote work implementation can be difficult in Japan.

Data were collected via news and public reports in two stages. First, I conducted data collection by using key words in Japanese, such as 'Covid-19,' 'remote work,' 'telework,' and 'Japan,' using a news archive in 6-16 January 2021. There appeared more than 100000 results in Google news search, and I briefly checked the top 300 hits to examine institutional cultural influence on the execution of remote work in Japan. Broad categories regarding HRM practices emerged in terms of why remote work may be hindered. These are types of recruitment, employment, appraisal, trainings, and daily routines and communication. Then, I used these practices for further search in order to see how these practices were conducted before and after Covid-19. At the second stage, I added some industry and government reports about remote work during Covid-19.

During the data analyses, these broad categories were sorted by the cause of hindrance of remote work into two social influences: institutional and cultural contexts in Japan. After the iterative process of theory and data collection, the sorting reached seven categories of HRM practices that can be constrained by institutions and culture in Japan: seniority-based HRM; long-term employment; processbased appraisal; teamwork; on-the-job training (OJT); overtime work; surveillance. 


\section{LITERATURE REVIEW AND THEORY DEVELOPMENT}

\section{Remote work emergence, its benefits, and drawbacks}

Following the Covid-19 pandemic and lockdown in Europe and North America in 2020, remote work quickly became a de facto work style. Many companies already adopted remote work, mainly for work-life balance, especially for employees with families. However, the Covid-19 pandemic triggered a rush towards remote work, making it crucial for business continuity. Reports by OECD (2020) show that remote work is a convenient and useful solution to the Covid-19 pandemic. During lockdowns, the public were required to isolate and quarantine themselves from the spread of Covid-19. They were also required to work from home whenever possible and not commute to work in their offices. Consequently, remote work has been required in all organizations (OECD, 2020; Ozimek, 2020). The OECD (2020) reports that how the remote work is implemented varies by country and company: highly skilled workers in knowledge-intensive industries, such as management education (e.g. Brammer \& Clark, 2020), are more suited for remote work than low-skilled workers in less knowledgeintensive industries and manufacturing. In addition, remote work could have some advantages, such as saving commute time, shorter work time, flexible working hours; while the disadvantages include overtime work, an unbalanced work-life ratio, and work intensification (George, Lakhani, \& Puranam, 2020; Leonardi, 2020; OECD, 2020). However, most literature regarding the matter focuses on Western countries, particularly North America and Europe.

Remote work is associated with productivity and wellbeing. Taking an example of a consulting firm, Dahik et al. (2020) conclude that perceived own productivity has increased through remote work, although there are variants in outcomes depending on functions. Remote work in the pandemic may have a profound impact on the well-being of employees, many of whom feel isolated from society. In a global survey of 2700 employees, Smith (2020) reports that $75 \%$ of all respondents feel socially isolated, while $67 \%$ of them feel highly stressed, while more than half feel high anxiety and are emotionally exhausted. However, this low level of wellbeing has to be carefully examined and independently analysed in remote work without the effects of the pandemic. Furthermore, this move towards remote work varies according to industry and organizations. For example, IT industries are used to this remote working style, and some made it a permanent style of work in the post-Covid-19 pandemic. In contrast, manufacturers continue to commute, produce, and ship products from site, as do other service industries - such as restaurants and cafes - possibly causing difficulties to adopt about remote work (e.g. Collings et al., 2021). The relationship between remote work productivity and well-being is even more complicated.

The existing literature tends to argue for the consequences and effects of remote work, on the assumption that remote work is inevitable and thus accepted thoroughly during the Covid-19 pandemic in Western countries. This may be so due to the fact that most studies focus on Western countries, both Europe and North America, where remote work had been accepted to some degree as a proper form of work. However, this may not be true in non-Western countries, such as Japan. By taking Japan as an example, the next subsection discusses the possibility that remote work albeit absolutely inevitable during the Covid-19 pandemic in the Western countries - may not be seen as useful outside of the Western world.

\section{Japanese HRM's institutional and cultural context}

As in Western countries, the Covid-19 pandemic forced the Japanese government to encourage remote work in all organizations (OECD, 2020; Ozimek, 2020). Indeed, the OECD (2020) indicates that how remote work is implemented varies according to country and company: highly-skilled workers in knowledge-intensive industries, such as management education (e.g. Brammer \& Clark, 2020), are more suited for remote work than low-skilled workers in less knowledge-intensive industries and manufacturing. In addition, remote work could have some advantages, such as saving commute time, shortening work time, and promoting flexible working hours; while the disadvantages include overtime work, an unbalanced work-life ratio, and work intensification (George et al., 2020; Leonardi, 2020; OECD, 2020). These advantages and disadvantages can also be found remote work in Japan (NIRA, 
2020a/b; COJ, 2020). However, the Japanese government has been promoting remote work for fulltime and part-time employees, and also for freelancers, since before the Covid-19 pandemic, and it had already set up a call centre, subsidiary, and seminars for remote work (MLHW, 2020).

This shift towards remote work may not be implemented in Japan as in the Western countries because of an institutional and cultural context of Japanese HRM. In the institutional context, senioritybased HRM has traditionally been a standard of Japanese HRM, although with some variations (Endo et al., 2015). Indeed, before the Covid-19 pandemic, Japan had less remote work than Western countries because it has a traditional work culture, in which employees are encouraged to collaborate with others through teamwork rather than relying on individual work-based performance: teamwork is promoted and evaluated without clear boundaries of individual responsibility rather than working as an individual. Japanese seniority-based HRM is usually associated with manufacturing plants and, thus, may not be accompanied with remote work because of the necessity to work on site (Sekiguchi, Froese, \& Iguchi, 2016). Furthermore, the dominant manufacturing sector in Japan, including large, small, and medium-sized firms, may hinder the execution of remote work due to the lack of resources and IT facilities, especially for small and medium-sized parts manufacturers (Gordon, 2017). The Covid-19 pandemic may also have led to a change from long-term to short-term employment. Moreover, Japan's tradition of process-oriented rather than results-oriented appraisals may hinder the execution of remote work (Sekiguchi et al., 2016). In contrast to the high adoption ratio of remote work in Scandinavian and Anglo-Saxon countries, with around $40-50 \%$ working remotely (OECD, 2020), a recent public report shows that remote work has gradually been adopted by around $30 \%$ of Japanese firms, who have either already adopted or will adopt remote work in the future (MIAC, 2020; NIRA, 2020a/b). This confirms a public report which shows that firms in the US adopted remote work swiftly and reduced the workforce (e.g. Bartik et al., 2020; Brynjolfsson et al., 2020).

Japan has less remote work than Western countries because it has a traditional work culture, in which employees are encouraged to collaborate with others through teamwork rather than relying on individual work-based performance: teamwork is promoted and evaluated without clear boundaries of individual responsibility. Indeed, remote work cannot be separated from communication styles between employees. In particular, Japan is characterized as a high-context culture (Hall, 1973) rather than low-context culture. This point is strongly implicated as to how remote work may not work well in the Covid-19 pandemic in a high-context culture (e.g, Singh \& Matsuo, 2004). In highcontext cultures, what is important besides message delivery and exchange are situational factors, external environments, and non-verbal communication. As in Southern European and Arabic countries, Japan is one of the most context-oriented countries in which paralanguage and facial expressions matter to communication as well as setting and timing of communication (Boyacigiller \& Adler, 1991). In contrast, clear and explicit messages are highly appreciated in low-context cultures, especially in Anglo-Saxon and Northern European countries. This low-context culture is likely to affect and perhaps hinder remote work because messages that include context are preferred. In addition, Japanese culture is characterized by collectivism, high-power distance, and paternalism. This may imply that Japan is unfit for remote work based on the assumption that work is assigned and monitored individually and remotely rather than through physical working together in an office (House, 2004; Hofstede, 2001; Hofstede, Hofstede, \& Minkov, 2010).

\section{RESULTS AND DISCUSSION}

\section{Institutional constraints on remote work}

The study identified three institutional constraints in terms of Japanese HRM practices: seniority, longterm employment, and process-oriented appraisal.

\section{Change from seniority- to performance-based HRM}

Before the Covid-19 pandemic, scholars widely acknowledged that Japan has gradually started to move from seniority-based to performance-based HRM. For example, Aoki et al. (2007) found that Japanese firms are becoming increasingly diverse in terms of their adopted HRM practices. Some studies em- 
phasised a shift to westernised HRM practices in Japan, with the gradual adoption of the concept of performance-based HRM instead of seniority-based HRMs (Morris et al., 2006; Keizer et al., 2012). Other studies indicate a divide between Japanese and westernised HRM practices according to the industry and foreign ownership (Morris et al., 2018). Manufacturers tend to keep seniority-based HRM more than non-manufactures, while active foreign shareholders tend to prefer to promote performance-based HRM than keeping seniority-based HRM. Studies provide a nuanced picture of the difference between adopting a westernised or keeping a traditional Japanese HRM. The persistent adoption of lifetime and long-term employment is often limited to core employees with full-time tenured contracts and does not extend to temporary or part-time contracts that do not guarantee employment until retirement age (as reported in Ministry of Health, Labour and Welfare; MHLW, 2020). Conventional HRM continues to persist in some traditional large Japanese firms, including manufacturers and service providers, who rely on subcontracting and hiring part-time workers. This report also shows that there is a mix of continuity and change in Japanese HRMs practices among small and medium-sized firms, while younger Japanese firms may adopt westernised HRM practices. Thus, for some Japanese firms, the seniority-based HRM is still an institutionally legitimate practice in Japan.

In the post-Covid-19 pandemic era, remote work may be limited only to those who adopt performance-based HRM rather than those who stick with traditional seniority-based HRM. Generally, remote work is more suited to the westernised performance-based HRM, which assumes that the managers plan, assign, monitor, and evaluate the jobs of subordinates, with a clear scope of command and control on an individual basis (Sekiguchi et al., 2016). Facing the necessity of remote work, Japanese HRM based on long-term employment and teamwork may need to be reconsidered. Otherwise, remote work may be treated as a temporary solution and will be forgotten as soon as the pandemic is over for those firms who tend to stick to traditional seniority-based HRM. Nevertheless, a change in HRM may be more closely associated with the industry and size of firms, as briefly indicated in a public report of Japanese firms in knowledge-intensive industries (e.g. IT and finance). Moreover, highlyskilled workers are likely to continue to adopt remote work in the post-Covid-19 era.

Thus, further research should focus on change and continuity in Japanese HRM via remote work in the post-Covid-19 era. In particular, how and why does remote work trigger change and or maintain continuity in HRM in Japan?

\section{Long-term and lifetime employment}

Before the Covid-19 pandemic, Japan's traditional long-term and lifetime employment had been at risk because of economic stagnation, as in the rest of the world (e.g. Verma \& Anders, 2020;). In particular, large multinational companies (e.g. automotive and electronic manufacturers) continued to restructure their businesses since the 2000s. For example, Panasonic announced its corporate restructuring in 2009 (Panasonic, 2009) and stated that it was going to reduce its workforce by around 10,000 employees. The tradition of long-term and lifetime employment resulted also from the choices made by Japanese firms, often influenced by factors such as best practices, corporate owners' and investors' profiles (e.g. Japanese or non-Japanese), and type of business (e.g. Morris et al., 2018). Nevertheless, long-term and lifetime employment can still be found in some large Japanese firms but is usually reserved for core employees with tenured contracts - hired as university graduates - and excludes peripheral employees with limited-term contracts and part-time employees (MHLW, 2020).

After the Covid-19 pandemic, remote work may be differently adopted according to types of employment, including both core and peripheral employees. On the one hand, core employees may continue remote work with secured employment, while on the other hand, peripheral employees will simply be dismissed. This may eventually accelerate into a more flexible form, possibly changing core employees into peripheral ones with temporary and part-time contracts, or more outsourcing may be used (MHLW, 2013). This change is already evident in macro data. For example, a government report shows a rise in the unemployment rate in Japan, from $2 \%$ in 2020 to nearly $3 \%$ in 2021, which echoes that of the rest of the world. Japan's increase in the unemployment rate is consistent with the rest of the world, such as the USA, where firms have increasingly laid off employees and reduced working time (Dey \& Loewenstein, 2020). Even large traditional Japanese manufacturers 
have started to question the efficiency of long-term and lifetime employment. For example, Akio Toyoda, the president of Toyota, announced that lifetime employment may no longer be sustainable. This statement was controversial and shook not only the automotive industry but also the rest of the industry in Japan (Toyotatimes, 2021). This parallels the corporate restructuring of Panasonic following its formal announcement that it would reduce workforce. This shift may become more apparent with the widespread adoption of remote work and the high unemployment rate following the Covid-19 pandemic. Nevertheless, remote work has the potential to reduce office costs and enable employees to work in a more productive manner, perhaps leading to a sustained or even increased use of long-term and lifetime employment.

Thus, further research should focus on remote work in relation to long-term and lifetime employment in the post-Covid-19 era. In particular, how is remote work utilized in long-term and lifetime employment?

\section{Process-oriented appraisal}

Before the Covid-19 pandemic, a process-oriented appraisal was evident in a series of studies conducted in 2010s. Some scholars emphasized a change from process-oriented towards results- and outcome-based appraisals. Keizer (2012) also concludes that process-based appraisals with seniority are replaced by results- and performance-based appraisals in some Japanese firms, a trend confirmed by Sekiguchi (2013). Indeed, Sekiguchi (2013) concludes that performance-based HRM practices - initially treated as a management fashion in the 1990s - had become institutionalized in Japanese firms. Other scholars found that traditional process-based evaluation with seniority remained in many Japanese firms. For example, Aoki et al. (2014) find that Japanese manufacturers shift towards a more American style in both domestic and international plants so as to improve labour productivity. These authors also illustrate that some Japanese manufacturers acquired by US multinational corporations (MNCs) adopt performance-based HRM across all levels of their organization, from managers to factory workers, while in other manufacturing companies' performance-based HRM is limited only to managers. Furthermore, a recent study by Morris et al. (2018) investigates both traditional large Japanese firms (e.g. electronic manufacturers and telecommunications providers) and non-traditional younger large Japanese firms (e.g. retailers and information technology providers). Therefore, performance appraisal methods may vary depending on the ratio of foreign shareholders who tend to push towards performance-based appraisals rather than simply the size and length of operations (MHLW, 2013; 2020). All in all, a process-oriented appraisal is still institutionally legitimate for those Japanese firms that adopt seniority-based HRM.

In the post-Covid-19 era, remote work may be renounced in those Japanese firms who stuck with a process-oriented appraisal simply because remote work is more fitted to results-based evaluation. In fact, the firms that adopted process-oriented evaluation currently face difficulties in evaluating the work process following Covid-19 (e.g. COJ, 2020; NIRA, 2020a; b). In particular, it is difficult for managers to evaluate the process of the subordinate's remote work because they had previously been able to monitor and closely communicate with them in the office. Consequently, the amount of overtime that employees do may increase when they work remotely, which is often perceived and evaluated positively at Japanese firms that have adopted process-oriented appraisals. In addition, this change matters not to staff but managers, who have subordinates to evaluate. For Japanese firms who had already adopted result-based evaluation, this change may be supported and reinforced by implementing remote work.

Thus, further research should focus on remote work in relation to both process- and results-oriented appraisals in the post-Covid-19 era. In particular, how can remote work be reconciled with the existing process-oriented evaluation or promote results-oriented evaluation?

\section{Cultural constraints on remote work}

The study identified four elements as possible practices in remote work that could be greatly affected by Japanese cultural characteristics: collectivism, high-context culture, high-power distance culture, and high-uncertainty avoidance (Hofstede, 2001; 2010). 


\section{Collectivism: Teamwork}

Before the Covid-19 pandemic, the importance of teamwork was already being implicitly questioned by a move towards performance-based HRM, manifesting the collectivist national culture (Hofstede, 2010; Abo, 2015). On the one hand, teamwork in Japan has long been emphasized in manufacturing operations, such as just-in-time, kaizen, nemawashi, and total quality management (e.g. Kotabe, 2020). The concept of teamwork has been used by large manufacturers because it enables workers to feel responsible for an end product, rather than the job that they are assigned to do. However, the concept of a team is not limited only to the individual level, such as teams and peers (e.g. Keiretsu can be seen as an interorganizational manifestation of teamwork). On the other hand, the conception of teamwork has been questioned and perhaps downplayed by those Japanese firms who adopted performancebased evaluation. Morris et al. (2018) demonstrate that performance-based evaluation may lead to the denial of teamwork because working as a team may conflict with individual performance. A performance-based HRM with a focus on individual evaluation goes hand-in-hand with anti-teamwork, which downplays the value of teamwork. Finally, the manufacturing industry has one of the lowest levels of adoption of remote work (NIRA, 2020a; b).

In the post-Covid-19 era, remote work may be limited to individual work rather than teamwork because the collectivistic tendency may remain unchanged. Indeed, as a core part of teamwork, the formerly conducted intensive communication among colleagues is very difficult in remote work (NIRA, 2020a; b). Some Japanese employees continue to commute to their offices despite the pandemic because of a perceived need of teamwork or simply because they follow their managers' orders. This aligns with the collectivist aspects of process-oriented evaluation and long-term orientation, especially apparent in manufacturing (e.g. COJ, 2020; NIRA, 2020a; b). Otherwise, the adoption of remote work might continue to be limited to non-manufacturing industries and highly knowledge-intensive sectors (OECD 2020). In addition, the limitation of socialization practices may affect the quality of teamwork because socialization helps employees to know and understand other team members and, thus, work towards shared goals (Brammer, Branicki, \& Linnenluecke, 2020).

Further research should focus on remote work and collectivist culture in relation to types of work, function, and industry in the post-Covid-19 era. In particular, how can teamwork coexist with or be reduced through remote work?

\section{High context culture: Training}

Before the Covid-19 pandemic, training at Japanese firms was provided by a combination of on-thejob (OJT) and off-the-job training, which is part of a high-context culture (Hall, 1973). In particular, OJT was a core part of Japanese manufacturers work on the assembly line, and it ensured that workers were able to learn tacit knowledge at work. In general, Japanese manufacturers proactively adopt OJTs on site and use apprenticeship in which fresh graduates are supposed to work together with experienced employees. This type of OJT goes hand-in-hand with the importance of on-site presence for Japanese firms to create knowledge (e.g. Nonaka et al., 2001). This type of apprenticeship is now mentorship-driven training in the talent management system (Hosomi, Sekiguchi, \& Froese, 2020). However, Japanese-styled training is a much more informal mentorship when compared with Western formal mentorship, which is in alignment with long-term and lifetime employment, informal network within a firm, and teamwork promotion. This strong preference for OJTs was strongly linked to the importance of organizational harmony and clan relationship between employees and organizations, which is often characterized as 'company as family' (Bhappu, 2000).

In the post-Covid-19 era, remote work may be abandoned for OJT activities online simply because it is not easy to implement OJTs. Remote work also limits constant communication with mentors, supervisors, and peers because they prefer to communicate not only with verbal but also non-verbal messages. In particular, OJTs assumed that supervisors and supervisees work together in the same office or on the shop floor. Here, supervisees can learn implicit and explicit knowledge by shadowing their supervisors, which may be limited by remote work. Otherwise, remote work may be equipped with new technologies to constantly connect supervisors and supervisees as part of OJTs. 
Thus, further research should focus on remote work and the implementations of OJTs in relation to types of work, function, and industry in high-context cultures in the post-Covid-19 era. In particular, how can remote work sustain or dismiss OJT in high-context rather than low-context communication?

\section{High power distance: Overtime work}

Before the Covid-19 pandemic, overtime work was a contentious topic in Japan that was frequently criticized and roundly condemned in the media discourse, which manifested a cultural construct of high-power distance between the managers and the managed (Hofstede, 2010). This was strongly linked to a trend characterizing Japanese firms as either black, white, or grey (e.g. Russell, 2017). On the one hand, black Japanese firms tend to exploit employees by relying on overtime work and they have a poor reputation. They pressure employees to illegally work overtime, they harass their employees, and they pay them few benefits. White Japanese firms tend to care about the health and wellbeing of their employees, have benefit programs, comply with employment law, and have a good reputation. Their employees are treated with respect, do less overtime work, are not harassed, and receive many benefits. Gray Japanese firms move between black and white. Overtime work in Japan is closely associated with overtime death, in which employees commit suicide or suffer heart attacks or strokes due to the pressures of overtime work. Overtime work is perceived very negatively but can be explained by different factors, such as molecular (genetic), micro (individual), meso (organizational), and macro (cultural) evolutionary forces (Timming, 2020).

In the post-Covid-19 era, remote work may either reduce or further increase overtime work in reference to power relationship between managers and the managed. On the one hand, overtime work could be increased by remote work, partially because employees may face a blurred boundary between work and life balance because their colleagues constantly send messages via email and chat applications (e.g. Morris \& Hassard, 2020), which possibly refers to gender issues and productivity in remote work (e.g. Feng \& Savani, 2020), particularly women with a family. These constant messages and persistent interruptions and distractions may unnecessarily prolong work time. In addition, those who live with families and children during the lockdown may face difficulties in their work time because they need to deal with work and life chores (NIRA, 2020). On the other hand, overtime work may be significantly decreased by remote work. Indeed, some employees may work more efficiently and in a shorter time in the post-Covid-19 era because they are freed from chores and unnecessary conversations caused in the office, and hence can work more productively.

Thus, further research should focus on remote work and overtime work in high power distance cultures in relation to types of work, function, and industry in the post-Covid-19 era. In particular, how can the problem of overtime work be solved by remote work in high power distance cultures?

\section{High uncertainty avoidance: Surveillance}

Before the Covid-19 pandemic, employees were expected to closely communicate with managers on site. Therefore, it was reasonably easy for managers to monitor how subordinates work in the office. In cross-cultural studies, this is characterized as part of high uncertainty avoidance, as frequently argued for the case of Japan (Hofstede, 2010). This is connected to the importance of the employee's attitude and personality rather than that of skills based on lifetime employment, which is closely associated with OJTs and process-oriented appraisal. The need to work on site is emphasized so that managers need to constantly stay in touch with and observe subordinates for evaluation, OJTs, teamwork, unity, and so on. Moreover, this is closely associated with overtime work, in which employees were observed to work longer than necessary so as to show a work process and hard they work in the office.

In the post-Covid-19 era, remote work may promote online surveillance for those who used to evaluate and be evaluated by how hard employees work on site (e.g. Hodder, 2020). In remote work, this may be connected to a need for managers to constantly observe and monitor whether or not the subordinates work properly without absence at home. Several technologies can already support managers who wish to monitor their subordinates as they did before the Covid-19 pandemic. For example, software applications such as KnockMe! and LOOOC can keep the employee's camera on and show their work on the monitor, which enables the managers to monitor and even interrupt 
whenever they want. However, this surveillance activity may raise legal issues regarding employees' privacy, and it may also breach employment law, as identified in the legal issues of remote work in Romania and Hungary (e.g. Vallasek \& Melypataki, 2020).

Thus, further research should focus on how remote work agrees with online surveillance systems in high and low uncertainty avoidance cultures. Furthermore, what should be examined in more depth is the relationship between firms in high and low uncertainty avoidance cultures, along with methods and frequency of online surveillance systems. In particular, are surveillance systems implemented for lower knowledge-intensive workers or lower knowledge-intensive industries in both high- and lowuncertainty avoidance cultures? If so, then why? And if not, then why not?

\section{CONCLUSIONS}

This article aimed to elaborate how the form of remote work can be hindered in the institutional cultural context of non-Western countries. By talking Japan as an example of non-Western countries, the study clarified how remote work can be hampered by institutional and cultural contexts in Japan. On the one hand, I identified institutional constraints in relatively formal HRM practices, such as seniority, long-term employment, process-oriented appraisal. On the other hand, I found cultural constraints in more informal and daily work and communication, such as teamwork, training, overtime, and surveillance.

This article implicates that the execution of remote work may not have been universally efficient as argued in the current literature based on cases from Western countries. This implication can be especially the case for those non-Western countries, such as Asian countries, where seniority and longterm employment are prioritized over performance and short-term results. Moreover, it can also be the case for those countries whose cultures prefer collectivism, high context communication, high power distance, and high uncertainty avoidance. This raises a serious concern about the assumption that remote work has been preferred and was even essential during and even after the pandemic as observed in the Western countries.

I should mention some research limitations of the above study. First, the research was based on news archives and reports published mainly in 2020 , thus this timeline may be short to conclude the institutional and cultural effects on remote work. However, this article shows some results regarding the possible institutional cultural constraints in Japan. Second, this study is based solely on the case of Japan, so it may not be generalizable to other non-Western countries. However, the article shows possible key constraints of remote work that have been heretofore almost neglected in the subject literature.

This article opens up new research avenues for the future. Possible research questions encompass such matters as how remote work can be hindered by institutional and cultural constraints in other non-Western countries, such as Asian and the others, which have similar institutional and cultural profiles to Japan? Another question could be how national culture enables remote work to be adopted across Western and non-Western countries.

\section{REFERENCES}

Abo, T. (2015). Researching international transfer of the Japanese-style management and production system: Hybrid factories in six continents. Asian Business \& Management, 14(1), 5-35. https://doi.org/10.1057/abm.2014.13

Aoki, K., Delbridge, R., \& Endo, T. (2014). 'Japanese human resource management' in post-bubble Japan. The International Journal of Human Resource Management, 25(18), 2551-2572. https://doi.org/10.1080/09585192.2012.722118

Aoki, M., Jackson, G., \& Miyajima, H. (2007). Corporate governance in Japan: Institutional change and organizational diversity. London: Oxford University Press.

Bartik, A.W., Cullen, Z.B., Glaeser, E.L., Luca, M., \& Stanton, C.T. (2020). What Jobs are Being Done at Home During the Covid-19 Crisis? Evidence from Firm-Level Surveys. NBER working paper. National Bureau of Ecnomic Research (NBER). Retrieved from https://www.nber.org/papers/w27422 on March 11, 2021. 
Bhappu, A.D. (2000). The Japanese family: An institutional logic for Japanese corporate networks and Japanese management. Academy of Management Review, 25(2), 409-415. https://doi.org/10.5465/amr.2000.3312926

Boyacigiller, N. (1990). The role of expatriates in the management of interdependence complexity and risk in multinational corporations. Journal of International Business Studies, 21(3), 357-381. https://doi.org/10.1057/palgrave.jibs.8490825

Brammer, S., \& Clark, T. (2020). COVID-19 and management education: reflections on challenges, opportunities, and potential futures. British Journal of Management, 31(3), 453-456. https://doi.org/10.1111/1467-8551.12425

Brammer, S., Branicki, L., \& Linnenluecke, M.K. (2020). COVID-19, Societalization, and the future of business in society. Academy of Management Perspectives, 34(4), 493-507. https://doi.org/10.5465/amp.2019.0053

COJ. (2020). The COVID-19 influence on lifestyle and behaviours in Japan. Retrieved from https://www5.cao.go.jp/keizai2/manzoku/index.html on March 13, 2021.

Collings, D.G., Nyberg, A.J., Wright, P.M., \& McMackin, J. (2021). Leading through paradox in a COVID-19 world: Human resources comes of age. Human Resource Management Journal, Online access only. https://doi.org/10.1111/1748-8583.12343

Dahik, A., Lovich, D., Kreafle, C., Bailey, A., Kilmann, J., Kennedy, D., ... \& Wenstrup, J. (2020). What 12,000 employees have to say about the future of remote work. Retrieved from https://www.bcg.com/publications/2020/valuable-productivity-gains-covid-19 on February 5, 2021.

Dey, M., \& Loewenstein, M.A. (2020). How many workers are employed in sectors directly affected by COVID-19 shutdowns, where do they work, and how much do they earn?. Monthly Labor Review, April 2020, 1-19. https://doi.org/10.2307/26915268

Erik Brynjolfsson, J.J.H., Ozimek, A., Rock, D., Sharma, G., \& TuYe, H-Y. (2020). COVID-19 and remote work: An early look at US data. NBER working paper. National Bureau of Economic Research (NBER). Retrieved from https://www.nber.org/papers/w27344 on February 5, 2021.

Feng, Z., \& Savani, K. (2020). Covid-19 created a gender gap in perceived work productivity and job satisfaction: implications for dual-career parents working from home. Gender in Management. An International Journal, 35(7/8), 719-736. https://doi.org/10.1108/GM-07-2020-0202

George, G., Lakhani, K.R., \& Puranam, P. (2020). What has changed? The impact of Covid pandemic on the technology and innovation management research agenda. Journal of Management Studies, 57(8), 1754-1758. https://doi.org/10.1111/joms.12634

Gordon, A. (2017). New and enduring dual structures of employment in Japan: The rise of non-regular labor, 1980s-2010s. Social Science Japan Journal, 20(1), 9-36. Retrieved from https://doi.org/10.1093/ssjj/jyw042 on February 5, 2021.

Hall, E.T. (1973). The silent language (Anchor Books Editions ed.). New York: Doubleday.

Hodder, A. (2020). New Technology, Work and Employment in the era of COVID-19: reflecting on legacies of research. New Technology, Work and Employment, 35(3), 262-275. https://doi.org/10.1111/ntwe.12173

Hofstede, G., Hofstede, G.J., \& Minkov, M. (2010). Cultures and Organizations: Software of the mind. New York and London McGraw Hill Professional.

Hofstede, G.H. (2001). Culture's Consequences: Comparing Values, Behaviors, Institutions and Organizations Across Nations. SAGE Publications.

Hosomi, M., Sekiguchi, T., \& Froese, F.J. (2020). Mentoring in Japan: A Systematic Review and Conceptual Model. In P. Kumar \& P. Budhwar (Eds.), Mentorship-driven Talent Management (pp. 43-65). Emerald Publishing Limited.

House, R.J., Hanges, P.J., Javidan, M., Dorfman, P.W., \& Gupta, V. (2004). Culture, leadership, and organizations: The GLOBE study of 62 societies. SAGE Publications.

Keizer, A., Umemura, M., Delbridge, R., \& Morgan, G. (2012). Japanese management 20 years on. ESRC/ESRC Advanced Institute of Management Research Executive Briefing. Retrieved from http://www.aimresearch.org/uploads/File/Publications/Executive\%20Briefings\%202/AIM_Japan_EB_FINAL.pdf on February 5, 2021.

Kotabe, M. (2020). Japanese management and the climate of the time. Asian Business \& Management, 19(1), 2535. https://doi.org/10.1057/s41291-019-00078-y

MHLW. (2013). White paper. Retrieved from https://www.mhlw.go.jp/wp/hakusyo/roudou/13/dl/13-15_02.pdf on February 5, 2021.

MHLW. (2020). White paper. Retrieved from https://www.mhlw.go.jp/stf/wp/hakusyo/kousei/19/index.html on February 5, 2021. 
MIAC. (2020). A survey of tele communication usage. Retrieved from https://www.soumu.go.jp/johotsusintokei/statistics/data/200529_1.pdf on February 5, 2021.

Morris, J., \& Hassard, J. (2020). Home Working? The Present and Future of How and Where We Work in the Context of COVID-19. Cardiff Business School - Cardiff University.

Morris, J., Delbridge, R., \& Endo, T. (2018). The layering of meso-level institutional effects on employment systems in Japan. British Journal of Industrial Relations, 56(3), 603-630. https://doi.org/10.1111/bjir.12296

Morris, J., Hassard, J., \& McCann, L. (2006). New organizational forms, human resource management and structural convergence? A study of Japanese organizations. Organization Studies, 27(10), 1485-1511.

Morris, J., Hassard, J., Delbridge, R., \& Endo, T. (2019). Understanding managerial work in the modern Japanese firm: The influence of new organizational forms and changing human resource management practices. Economic and Industrial Democracy, online access only 0143831X19875785. https://doi.org/10.1177/0143831x19875785

NIRA. (2020a). A survey of employees conducting tele work (2nd). Retrieved from https://www.nira.or.jp/outgoing/report/entry/n200805_983.html; https://www.nira.or.jp/pdf/report202008-1.pdf on February 5, 2021.

NIRA. (2020b). A survey of employees conducting tele work (3rd). Retrieved from https://www.nira.or.jp/outgoing/report/entry/n201229_996.html on February 22, 2021.

Nonaka, I., \& Nishiguchi, T. (2001). Knowledge emergence: social, technical, and evolutionary dimensions of knowledge creation. London: Oxford University Press.

OECD. (2020). OECD Policy Responses to Coronavirus (COVID-19). Productivity gains from teleworking in the post COVID-19 era: How can public policies make it happen?. Retrieved from https://www.oecd.org/coronavirus/policy-responses/productivity-gains-from-teleworking-in-the-post-covid-19-era-a5d52e99/ on February 5, 2021.

Ozimek, A. (2020). The Future of Remote Work. Available at SSRN 3638597. Retrieved from https://doi.org/10.2139/ssrn.3638597 on February 22, 2021.

Panasonic. (2009). Panasonic Announces Business Restructuring and Growth Strategy for its Motor Business [Press release]. Retrieved from https://news.panasonic.com/global/press/data/en091102-5/en0911025.html on February 5, 2021.

Russell, J.G. (2017). Replicating the white self and other: Skin color, racelessness, gynoids, and the construction of whiteness in Japan. Japanese Studies, 37(1), 23-48. https://doi.org/10.1080/10371397.2017.1297183

Scott, W.R. (2008). Institutions and organizations: Ideas and interests (3rd ed.). Los Angeles: Sage.

Sekiguchi, T. (2013). Theoretical implications from the case of performance-based human resource management practices in Japan: management fashion, institutionalization and strategic human resource management perspectives. The International Journal of Human Resource Management, 24(3), 471-486. https://doi.org/10.1080/09585192.2012.703414

Sekiguchi, T., Froese, F.J., \& Iguchi, C. (2016). International human resource management of Japanese multinational corporations: Challenges and future directions. Asian Business \& Management, 15(2), 83-109. https://doi.org/10.1057/abm.2016.5

Singh, N., \& Matsuo, H. (2004). Measuring cultural adaptation on the Web: a content analytic study of U.S. and Japanese Web sites. Journal of Business Research, 57(8), 864-872. https://doi.org/10.1016/S01482963(02)00482-4

Smith, R. (2020). How CEOs can support employee mental health in a crisis. Harvard Business Review. Retrieved from https://hbr.org/2020/05/how-ceos-can-support-employee-mental-health-in-a-crisis on February 10, 2021.

Timming, A.R. (2020). Why competitive productivity sometimes goes too far: a multilevel evolutionary model of "karoshi". Cross Cultural \& Strategic Management, 28(1), 96-107. https://doi.org/10.1108/CCSM-02-2020-0027

Toyotatimes. (2021). JAMA Chairman Akio Toyoda Delivers New Year Message. Toyotatimes. Retrievedfrom https://toyotatimes.jp/en/insidetoyota/112.html on March 11, 2021.

Vallasek, M., \& Mélypataki, G. (2020). Rules on home office work and telework in Romania and in Hungary. Central European Journal of Comparative Law, 1(2), 177-191.

Verma, S., \& Gustafsson, A. (2020). Investigating the emerging COVID-19 research trends in the field of business and management: A bibliometric analysis approach. Journal of Business Research, 118, 253-261. https://doi.org/10.1016/j.jbusres.2020.06.057

Work in the Context of COVID-19. (2020). Cardiff Business School COVID-19 and Work WP 2020, Cardiff University Retrieved from https://higherlogicdownload.s3.amazonaws.com/AOM/6f82acc5-5f6b-41fb-a485f1639ebcf18c/UploadedImages/Homeworking_2_.pdf on February 5, 2021. 


\section{Author}

\section{Hitoshi Iwashita}

Academic researcher and teacher of cross-cultural management in multinational firms. His continuing interest lies in developing theory and practice regarding Japanese management in a cross-cultural context with a focus on leadership, culture, organizational behaviour, and strategy in Asia and other regions. As a corporate educator and consultant, he delivered a number of consulting projects to Japanese multinational corporations facing cross-cultural issues on strategy, post integration, organizational development, and leadership. He completed an International MBA from IE Business School and received a PhD in Business and Management from Cardiff Business School. He was formerly a management consultant, helping large Japanese multinationals to build strategy and leadership in cross-cultural environments.

Correspondence to: Dr Hitoshi Iwashita, Vietnamese German University, Faculty of Economics and Management, Ho Chi Minh City, Le Lai Street, Hoa Phu Ward, Thu Dau Mot City, Binh Duong Province, Vietnam, e-mail: hitoshi.iwashita@vgu.edu.vn

ORCID 가 http://orcid.org/0000-0002-4173-9341

\section{Conflict of Interest}

The author declares that the research was conducted in the absence of any commercial or financial relationships that could be construed as a potential conflict of interest.

\section{Copyright and License}

This article is published under the terms of the Creative Commons

Attribution - NoDerivs (CC BY-ND 4.0) License

http://creativecommons.org/licenses/by-nd/4.0/

Published by Cracow University of Economics - Krakow, Poland 